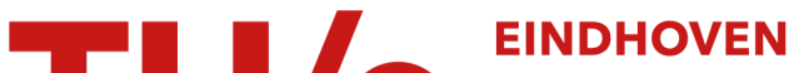 \\ UNIVERSITY OF \\ TECHNOLOGY
}

\section{Leaky-wave slot array antenna fed by a dual reflector system}

Citation for published version (APA):

Ettorre, M., Neto, A., Gerini, G., \& Maci, S. (2008). Leaky-wave slot array antenna fed by a dual reflector system. In Proceedings of IEEE Antennas and Propagation Society International Symposium, 2008, AP-S 2008, 05-11 July 2008 San Diego, CA (pp. 1-4). Institute of Electrical and Electronics Engineers.

https://doi.org/10.1109/APS.2008.4619390

DOI:

10.1109/APS.2008.4619390

Document status and date:

Published: 01/01/2008

\section{Document Version:}

Publisher's PDF, also known as Version of Record (includes final page, issue and volume numbers)

\section{Please check the document version of this publication:}

- A submitted manuscript is the version of the article upon submission and before peer-review. There can be important differences between the submitted version and the official published version of record. People interested in the research are advised to contact the author for the final version of the publication, or visit the $\mathrm{DOI}$ to the publisher's website.

- The final author version and the galley proof are versions of the publication after peer review.

- The final published version features the final layout of the paper including the volume, issue and page numbers.

Link to publication

\section{General rights}

Copyright and moral rights for the publications made accessible in the public portal are retained by the authors and/or other copyright owners and it is a condition of accessing publications that users recognise and abide by the legal requirements associated with these rights.

- Users may download and print one copy of any publication from the public portal for the purpose of private study or research.

- You may not further distribute the material or use it for any profit-making activity or commercial gain

- You may freely distribute the URL identifying the publication in the public portal.

If the publication is distributed under the terms of Article 25fa of the Dutch Copyright Act, indicated by the "Taverne" license above, please follow below link for the End User Agreement:

www.tue.nl/taverne

Take down policy

If you believe that this document breaches copyright please contact us at:

openaccess@tue.nl

providing details and we will investigate your claim. 


\title{
Leaky-Wave Slot Array Antenna Fed by a Dual Reflector System
}

\author{
M. Ettorre ${ }^{(1)}$, A. Neto ${ }^{(1)}$, G. Gerini ${ }^{(1)}$, S. Maci ${ }^{(2)}$
}

(1) TNO - Defence, Security and Safety, Oude Waalsdorperweg 63, 2597 AK, The Hague, The Netherlands. E-mail : andrea.neto, mauro.ettorre, giampiero.gerini@tno.nl (2) University of Siena, Siena Italy, E-mail: macis@dii.unisi.it

\section{Introduction}

Planar leaky-wave antennas (LWAs) have received much attention in the recent years [1] for applications in the millimeter-wave ranges. In particular the compatibility with printed circuit board technology (PCB) and the low profile are the strongest features of these antennas. Mono dimensional planar leaky-wave antennas, as in [2], are characterized by a fun beam; then, array solutions or two-dimensional planar leakywave antennas are needed to radiate a pencil beam. An array solution of mono dimensional planar leaky-wave antennas would have the disadvantages of a cumbersome feeding network accompanied by a probable low efficiency. On the other hand two-dimensional leaky-wave antennas have the advantage of absence of the feeding network, but they are less flexible for beam shaped designing. The pencil beam leaky-wave antenna presented here, an array of slots etched on one plate of a parallel plate waveguide (PPW) is fed by a dual offset Gregorian reflector system realized by vias connecting the two plates of the PPW. The antenna is shown in Fig.1.
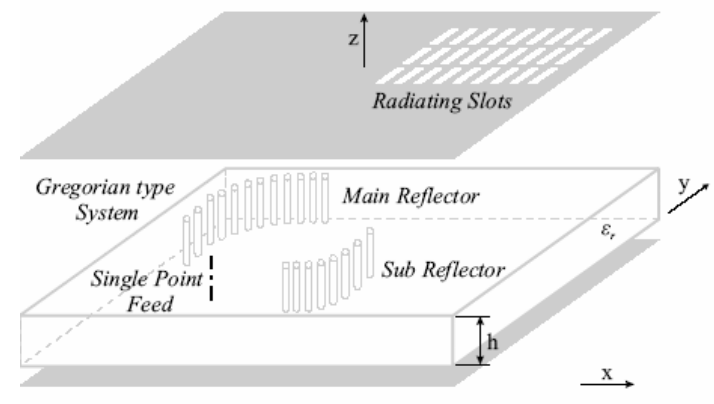

(a)

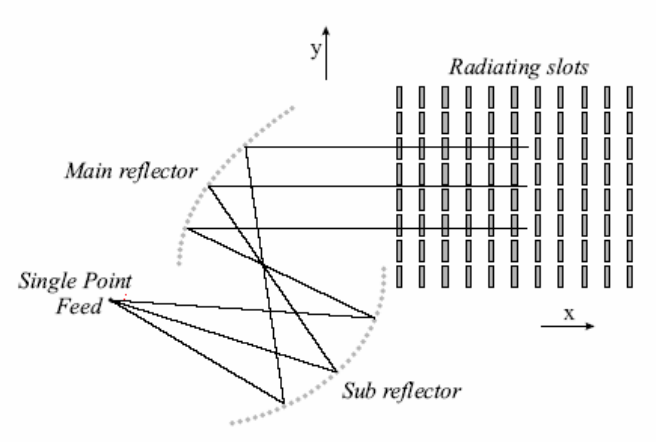

(b)

Fig. 1. (a) 3-D view of the antenna. The dual reflector feed system is made by pins connecting the two plates of the parallel plate waveguide. (b) Top view of the antenna. 
A probe-type source has been used to feed the Gregorian system which effectively implements a Mizughchi [1] condition so that it is possible to feed the reflector off focus without significantly altering the off focus beam performances. This arrangement is suited to printed circuit board fabrication processes. Furthermore it has the advantage to avoid a beam forming network while preserving the freedom to shape the amplitude of the plane feeding wavefront. The azimuth and elevation plane of the slot array can be thus shaped independently by acting on the focal plane feeding of the Gregorian system and on the parameters of the leaky-wave radiating slots. This leads various degree of freedom in the design. In particular a frequency reuse scheme renders possible the scanning in the E-plane, while a multi-feed focal plane renders possible the scanning in the E-plane. Overall this solution opens possibilities for those applications that are right now implemented with 3-D focusing imaging-like systems.

\section{Radiating slots}

The radiating part of the system is composed by an array of slots etched on the upper plate of a parallel plate waveguide structure, operating in a backward leaky-wave mode. In the working bandwidth $(9.1-9.6 \mathrm{GHz})$, the periodicity of the slots gives reason of a backward radiation in the $x^{2} \leftarrow z \psi$ plane.

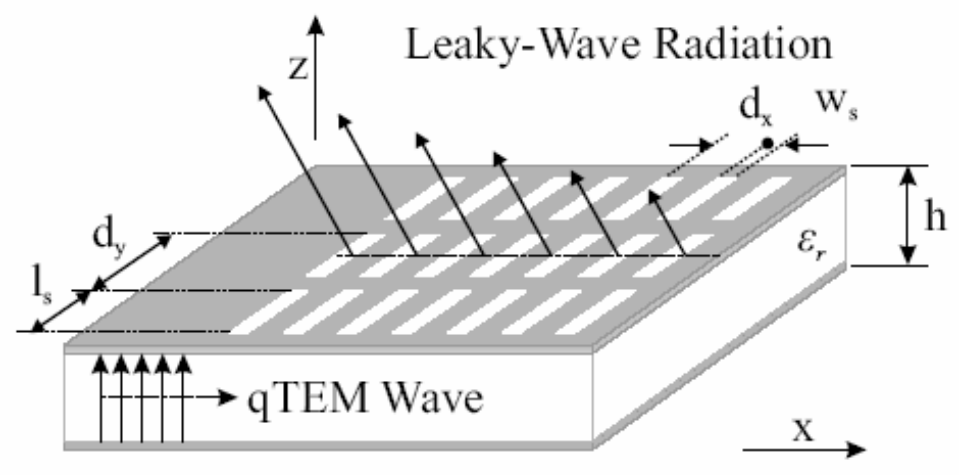

Fig. 2. Geometry of the radiating slots. The slots are etched on the upper plate of the parallel plate waveguide. The operating frequency is such as to have a backward radiation.

While the procedure to derive the dispersion equation characterizing such a structure will not be given here, it is important to highlight the effect of the most significant geometrical parameters that affect the dispersion equation. These considerations will give approximate equations to predict the radiation proprieties of the slots. In particular the basic radiation mechanism is the following. In absence of the slots a $q T E M \psi$ plane wave would propagate along the surface with real propagation constant $k_{q T E M} \psi$ essentially equal to $k_{0} \varepsilon \epsilon_{r}$. When the $q T E M \psi$ wave encounters the slot region, part of the energy reflects back in form of $q T E M \psi$ plane wave and part progresses in the slotted waveguide region in form of leaky-wave. The dominant -1-indexed $L W \psi$ of the Floquet mode expansion for periodic structures is the radiating one. It follows that the leaky wave beam angle can be approximated as:

$$
\theta \approx \sin ^{-1}\left(\frac{k_{x o}(\omega)-\frac{2 \pi}{d_{x}}}{k_{0}}\right)
$$

It is apparent from (1) that the beam pointing angle exhibits a variation vs. frequency which is caused by the non linearity of $k_{x^{\prime} 1}$ - with frequency, also within the first 
approximation that assumes that the zero mode runs with the phase velocity of the incident wave, i.e. $\psi k_{x 0}=\psi k_{q T E M \triangleright}$ ). The differences between the real radiation angle measured or calculated with full wave techniques,[3], and the angle according to the present simplification is in the order of 20 degrees and thus one can use the simplified formula as starting design point.

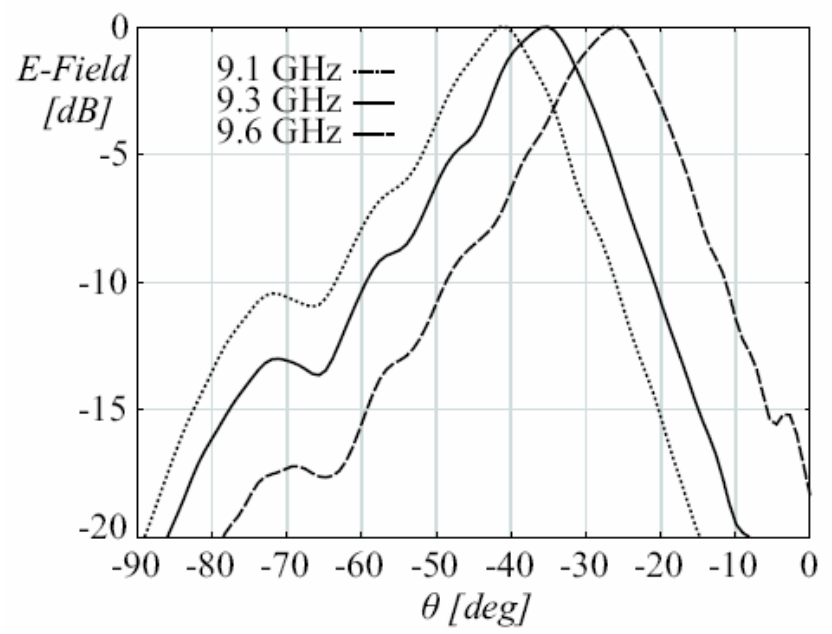

Fig. 3. Measured radiation patterns in the E-plane at different frequencies. $\theta \psi$ is the usual elevation angle starting from the normal to the plane of the antenna.

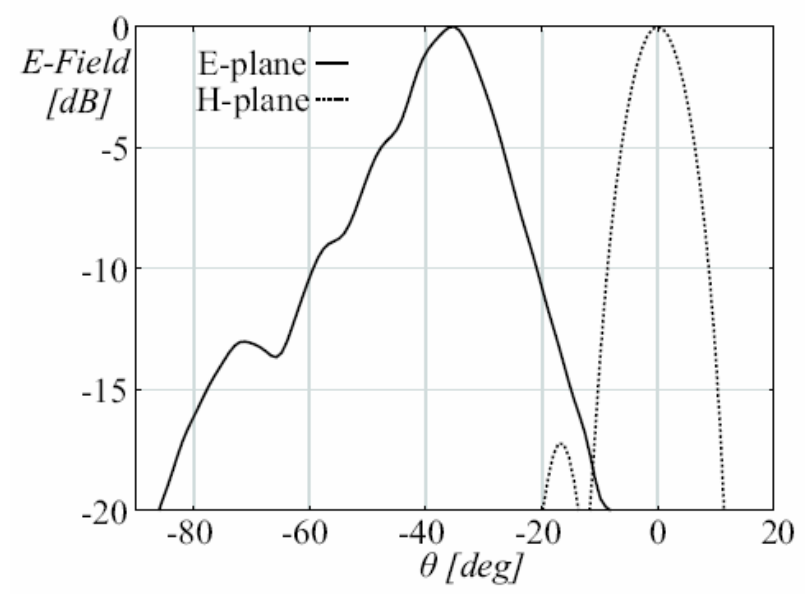

Fig. 4. Measured Radiation Patterns: electric field at the frequency $(9.3 \mathrm{GHz})$ on the Eplane and H-plane. $\theta \psi$ is the usual elevation angle starting from broadside for the Eplane and from the direction of maximum radiation for the H-plane.

\section{Prototype and experimental results}

An antenna prototype has been built and measured. For any part of the antenna the dimensions given previously have been used. Moreover the number of radiating slot rows have been chosen to reduce the surface wave field at the last row of slots to less than $1 / 10$. The number of slot rows is 23 . The antenna dimensions are $378 \times 596-\mathrm{mm} \psi$ while the panel size where the antenna is built is $457 \times 610-\mathrm{mm}$. For the dielectric a laminate Rogers RT Duroid 5880 has been used. The reflection coefficient and the radiation patterns of the antenna have been measured. The normalized measured radiation pattern as a function of the frequency is shown in Fig. 3. Fig. 4 shows the measured radiation patterns on the E-plane and H-plane at the frequency $f \psi=-9.3$ $G H z$. On the E-plane we observed a $-3-d B \psi$ beam-width of $B W \psi 12.6^{\circ} \leftarrow$ and on the $\mathrm{H}-$ 
plane of $B W \leftarrow 9.9^{\circ}$. The patterns on these two planes could be shaped independently within a certain degree of freedom. In fact the pattern on the E-plane is dictated by the leaky wave contribution. In particular the $-3-d B \psi$ beam width is proportional to the attenuation constant of the leaky wave and the pointing angle is related to the propagation constant of the leaky wave. The pattern on the H-plane is linked to the dual reflector system and then to its physical dimensions and type of feeding.

\section{Conclusion}

A dual offset Gregorian system leaky-wave antenna realized in PCB technology has been presented. An antenna prototype has been manufactured and tested. The measured radiation patterns as a function of the frequency have been presented. A pins-made feed, that uses EBG concepts, PCB extension of the one presented in [4] has been used to efficiently feed the dual reflector system. However it has not been discussed here for the sake of brevity. Good performance of the antenna has been observed. The planar dual reflector system could be used in future planar imaging system applications, to achieve antennas with independent beams in the azimuth and elevation planes, resorting to frequency reuse and multiple focal plane feeds. The scanning of the pointing angle with the frequency is observed. In particular since the final user of these antenna is a radar system whose beam is scanned as a function of the frequency, the frequency squint that was observed in Fig. 3 should not be considered a disadvantage.

\section{References}

1] T. Zhao, D. R. Jackson, J. T. Williams, H. D. Yang, A.A Oliner, "2-D Periodic Leaky-Wave Antennas- Part I and Part II: Metal Patch and slot Designs", IEEE Transactions on Antennas and Propagation, Vol. 53, no.11, pp. 3505- 3514 and pp. 3515-3524, Nov. 2005.

[2] M. Ettorre, S. Bruni, N. Llombart, A. Neto, G. Gerini, S. Maci, "Multi sector EBG Antenna for high directivity ......", IEEE Antennas Wireless and Propagation Letters, AWPL, Vol. 6, 2007

[3] Y. Mizughchi, A. Akagawa, H. Yokoi, "Offeset Gregorian antenna", Trans Inst. Electron. Commun. Eng. Japan, Vol. 161-B, no.3, pp. 166-173, Mar. 1978.

[4] A. Neto, N. Llombart, G. Gerini, M. D. Bonnedal, P. De Maagt, "EBG Enhanced Feeds for the Improvement of the Aperture Efficiency of Reflector Antennas", IEEE Transactions on Antennas and Propagation, Vol. 55, no.8, pp. 2185-2193, Aug. 2007. 